\title{
Factors associated with study attrition in a pilot randomised controlled trial to explore the role of exercise-assisted reduction to stop (EARS) smoking in disadvantaged groups
}

\author{
T. P. Thompson 1*, C. J. Greaves², R. Ayres ${ }^{1}$, P. Aveyard ${ }^{3}$, F. C. Warren², R. Byng ${ }^{1}$, R. S. Taylor ${ }^{2}$, J. L. Campbell ${ }^{2}$,
} M. Ussher ${ }^{4}$, S. Michie ${ }^{5}$, R. West ${ }^{6}$ and A. H. Taylor ${ }^{1}$

\begin{abstract}
Background: Study attrition has the potential to compromise a trial's internal and external validity. The aim of the present study was to identify factors associated with participant attrition in a pilot trial of the effectiveness of a novel behavioural support intervention focused on increasing physical activity to reduce smoking, to inform the methods to reduce attrition in a definitive trial.

Methods: Disadvantaged smokers who wanted to reduce but not quit were randomised $(N=99)$, of whom 61 (62\%) completed follow-up assessments at 16 weeks. Univariable logistic regression was conducted to determine the effects of intervention arm, method of recruitment, and participant characteristics (sociodemographic factors, and lifestyle, behavioural and attitudinal characteristics) on attrition, followed by multivariable logistic regression on those factors found to be related to attrition.

Results: Participants with low confidence to quit, and who were undertaking less than 150 mins of moderate and vigorous physical activity per week at baseline were less likely to complete the 16-week follow-up assessment. Exploratory analysis revealed that those who were lost to follow-up early in the trial (i.e., by 4 weeks), compared with those completing the study, were younger, had smoked for fewer years and had lower confidence to quit in the next 6 months. Participants who recorded a higher expired air carbon monoxide reading at baseline were more likely to drop out late in the study, as were those recruited via follow-up telephone calls. Multivariable analyses showed that only completing less than 150 mins of physical activity retained any confidence in predicting attrition in the presence of other variables.
\end{abstract}

Conclusions: The findings indicate that those who take more effort to be recruited, are younger, are heavier smokers, have less confidence to quit, and are less physically active are more likely to withdraw or be lost to follow-up.

Keywords: Retention, Drop out, Physical activity, Smoking reduction, Harm reduction

\footnotetext{
* Correspondence: tom.thompson@plymouth.ac.uk

'Plymouth University Peninsula School of Medicine and Dentistry, Plymouth, UK

Full list of author information is available at the end of the article
} 


\section{Background}

Participant attrition within research trials poses a threat to internal validity (attrition bias) [1], external validity (retained participants may not reflect practice) and loss of statistical power (reduced number of participants). Strategies to minimise attrition, such as knowing when and where to direct resources, may also have implications for the cost of conducting trials due to additional researcher time necessary to capture follow-up data [2]. Pilot trials can help to identify factors associated with study attrition and provide valuable information for the planning of a definitive trial, such as providing options for mode of participation (e.g. face-to-face assessments, telephone interviews, or postal questionnaires) [3] and identifying which participants are more likely to drop out and when to allow effective planning to maximise retention of participants..

It is usual for smoking cessation intervention trials to utilise intention-to-treat (ITT) analyses with an assumption that a participant lost to follow-up is still smoking (baseline observation carried forward) [4]. This assumption is problematic, as it could bias results and statistical tests in favour of an effective treatment if attrition rates are higher in the control group, as there is some evidence to suggest that those lost to follow-up in such trials may not necessarily be smoking [5-9]. Different approaches to handling missing data on smoking status at follow-up have been suggested, which may provide more reliable estimates of treatment effects [10-12]. However, all approaches rely on making assumptions about the missing data. It is therefore important to understand the factors influencing attrition to allow for more informed approaches to handling missing data, and to identify ways to minimise attrition in future smoking studies. This could be especially true of trials involving low socioeconomic groups where attrition rates may be greater than for other groups.

Studies involving interventions to support 'abrupt' smoking cessation report a wide range of attrition rates. In a review of RCTs of individual behavioural counselling interventions for smoking cessation [13], attrition rates (where reported) ranged from $1.7 \%$ [14] to $22.4 \%$ [15] at 6 months' follow-up and from $3 \%$ [16] to $31 \%$ [17] at 12 months' follow-up. A review of RCTs of interventions combining behavioural counselling and pharmacological support [18] identified a range of attrition rates from as low as 4-8\% [19] in one study and up to 24-30\% [20] in another at 6 months' follow-up, and between $7 \%$ [21] to $52 \%$ [22] at 12 months' follow-up in two other studies. Although one study identified in the review saw an attrition rate $<5 \%$ at 24 months' follow-up [23] it targeted inpatients with acute coronary syndrome who were probably more accessible for follow-up, compared with participants in the community. In contrast, a review of self-help interventions for smoking cessation [24], representing the least intensive level of intervention, included studies with attrition rates ranging from $11 \%$ [25] to $66 \%$ [26] at 6 months' follow-up and $<10 \%$ [27] to $56 \%$ [28] at 12 months' follow-up.

Despite there being 60 systematic reviews on the Cochrane Database on the effectiveness of interventions for smoking cessation [4], little attention has been given to identifying the factors associated with study attrition. The factors associated with attrition in studies concerned with smoking reduction or involving disadvantaged smokers $[29,30]$ are particularly poorly understood, due to a small number of such studies.

A number of factors may influence attrition including: (i) the nature of the intervention (e.g., clinical trials of an investigational medicinal product (CTIMPs) versus clinical trials of complex behavioural interventions (nonCTIMPs); (ii) the population characteristics (e.g., socioeconomic status, demographics); (iii) the study design (e.g., length of time to follow-up, burden of data collection on participant); and (iv) specifically among smoking trials, a focus on abrupt smoking cessation versus smoking reduction.

Smoking reduction is increasingly recognised as a viable alternative to the traditional abrupt smoking cessation approach, with flexible outcome measures [31], and it is unclear if there is any difference between these approaches on attrition. A review comparing interventions involving smoking reduction or abrupt cessation [32] included ten studies with attrition rates ranging from $19.1 \%$ [33] to $21-24 \%$ [34] at 6 months, and 11-13\% [35] to $64 \%$ [36] at 12 months but there appeared to be no difference in attrition between those reducing their smoking before quitting or stopping abruptly.

There have been no reports of when certain participants are likely to drop out, and given the progressive nature of smoking cessation and reduction it is likely certain participants may be more or less likely to withdraw at different times (i.e., time of dropout may be predicted by baseline characteristics such as confidence and importance to cut down or quit). Understanding these potential predictors of when a participant is likely to drop out would allow trialists to better plan resource use and direct support to participants at certain times to maximise the retention of participants.

Exercise as an aid to smoking cessation has been acknowledged as a feasible intervention for supporting cessation, yet the number of rigorous studies remains limited: there were only 15 studies included in the latest Cochrane review on the topic [37], 7 of which included fewer than 25 participants. Of the studies identified in this review, attrition rates varied from $0.3 \%$ [38] to $60.8 \%$ [39] at 6 months and from $0.5 \%$ [40] to $68-75 \%$ [41] at 12 months. The heterogeneity of research designs 
and methods among these studies makes it difficult to identify any factors associated with attrition, but attrition rates seem high compared with other studies involving interventions for smoking cessation.

Other studies which present attrition rates from smoking cessation studies with specific populations also present similar attrition rates to the smoking studies more generally. A study on exercise and counselling for smoking cessation for those with current depressive disorders reports attrition rates of $20 \%$ and $37 \%$ for the intervention and control respectively [42]. Another exercise counselling for smoking cessation among depressed women [43] reports slightly higher attrition rates of $35 \%$ at 10 weeks with no difference between arms. A recent study using exercise to support pregnant smokers to quit reported $11 \%$ attrition for unexplained reasons [44]. A study supporting homeless people to quit [45] reports $25 \%$ attrition at 26 weeks with no difference between study arms. As with the broader smoking cessation literature, the reported cessation rates among specific populations are varied and within similar ranges, suggesting specific characteristics may not impact on overall attrition rates.

There are few studies on the effectiveness of interventions for smoking cessation among low socioeconomic groups. In a recent review of low-income groups and health-behaviour change interventions [46] only 13 studies were identified, and of those only 7 targeted smoking behaviour, and no studies examined potential predictors of and reason for study attrition. None of the identified studies focused on smoking reduction among low socioeconomic groups.

Some authors suggest that attrition rates are generally higher in the control condition [10-12], but in the literature we reviewed some studies showed greater attrition in the control or intervention arm, and the majority showed no difference between trial arms. A metaanalysis of a random sample of 100 randomised controlled trials (RCTs) published in medical journals (with a range of participants and interventions) also showed no differential attrition between intervention and control conditions [47].

Several factors have been associated with increased attrition in smoking trials among various populations, including a higher Fagerström Test for Nicotine Dependence (FTND) score [48], a lower intention to quit [49], low self-efficacy and a longer smoking history [25], and the number of cigarettes smoked per day [50-52]. It is commonly believed that attrition within smoking cessation studies is driven by failure to maintain a successful quit attempt, where the individual will no longer seek support once they have reinitiated smoking as it holds no value if they are smoking again. This could be why factors associated with failing to quit (such as level of addiction and dependence) are related to attrition. Less is known in relation to failure to reduce as a predictor of attrition.

The aim of this study is to identify the factors associated with participant attrition in a pilot RCT on the effectiveness of a novel Exercise-Assisted Reduction then Stop (EARS) intervention (HTA number 07/78/02, ISRCTN 13837944, UKCRN Study ID 8937) among disadvantaged smokers. EARS recruited a disadvantaged population assessed by predetermined criteria (e.g., $91 \%$ were social class $\mathrm{C} 2-\mathrm{E}$ and $41 \%$ indicated mental health problems), the details of which have been published elsewhere [53]. The specific objectives of this study are to determine if features of the trial design and methods, and participant characteristics, are associated with participant attrition, to inform the design and methods for a definitive trial.

\section{Methods}

\section{Participants}

Ethical approval for the study was granted by the National Health Service (NHS) National Research Ethics Service Committee South West, in the UK. Recruitment took place in the neighbourhoods of Devonport and Stonehouse (Plymouth, UK), which are among the $3 \%$ most deprived areas in the UK. The recruitment methods, factors influencing recruitment, and baseline characteristics of the sample, have been reported elsewhere [54]. In summary, 99 adult moderate to heavy smokers, who wanted to reduce smoking (without nicotine replacement therapy (NRT)) but had no plans to quit in the next month, were recruited by either a mailed invitation from their general practitioner or NHS Stop Smoking Services (SSS), with follow-up telephone calls, or through other community approaches.

\section{Procedures}

After providing informed consent and baseline information, participants were randomised to receive either usual care (consisting of brief advice on smoking cessation services) or usual care plus the EARS intervention (consisting of up to 12 weekly client-centred individual support sessions, via telephone or in person, to assist with making self-directed changes in smoking and physical activity behaviour). Participants in either arm of the trial expressing the desire to quit were offered the chance to be referred to local SSS for specialist support.

Follow-up assessments were completed at 4, 8, and 16 weeks post-randomisation. For those who missed follow-up appointments, up to five attempts were made by telephone to reschedule the appointment; the rescheduled appointment could take place up to the halfway point between the missed appointment and the next follow-up. After the halfway point attempts were made to schedule the next follow-up appointment. Those who could not be contacted at all were classified as having dropped out of 
the study. Reasons for withdrawal were recorded for those who explicitly withdrew consent to participate in the study.

\section{Measures}

At baseline the following data were collected: participant demographic information (i.e., age, sex, marital status, cohabiting with other smokers, parental status (single parent living with a dependent under 16 years of age), employment status (employed or not), job status (social class), age of leaving full-time education, ethnicity, weight, and height), smoking history (age participant started smoking, longest period of cessation in the last year, attempts at cutting down, cessation aids used in the past year, use of SSS), number of cigarettes being smoked per day, Fagerström Test for Nicotine Dependence (FTND; $[55,56])$ scores, stage of readiness to use physical activity to control smoking behaviour, expired air carbon monoxide (CO), and physical activity data (subjectively by self-report of the previous 7 days and objectively by accelerometer). Follow-up assessments captured data on smoking- and physical activity-related behaviours and attitudes. In order to ensure compliance with wearing and returning accelerometers (costing approximately $£ 250$ each) we initially paid participants $£ 10$ for returning the accelerometer at each time point (except week 4 when they were not worn). This was increased to $£ 30$ at each time point when it was observed a considerable number had not been returned about a third of the way through the study. No other payment was made to participants for completing assessments other than reimbursing travel expenses. For the purposes of the present study, those lost to follow-up before the final follow-up (week 16) was the primary binary outcome. We also classified participants as dropping out early or late: early dropouts were those who did not complete any assessment after baseline, and late dropouts were those who failed to complete follow-up assessments after week 4 . Field notes were maintained to capture qualitative reasons for attrition as reported by withdrawing participants and as observed by researchers.

\section{Data analysis}

To determine the factors associated with study attrition at 16 weeks, binary logistic regression was performed and odds ratios (OR) reported with $95 \%$ confidence intervals (95\% CI). Intervention arm, method of recruitment, participant demographics, and lifestyle, behavioural, and attitudinal characteristics were individually examined as determinants of attrition, based on existing literature and the researchers' a priori reasons for their inclusion. Following the univariable analyses, each significant predictor of attrition was then added to multivariable logistic regression. Further exploratory analysis sought to compare those who dropped out earlier (before week 4), later (after week 4), or completed the study. Attrition status (early dropout, late dropout or completion) was analysed using multinomial logistic regression, with inclusion of each covariate individually in a separate univariable model, followed by the inclusion of the variables related to attrition in a multivariable multinomial logistic regression model. Multinomial logistic regression was chosen in place of ordinal logistic regression as the three categories were considered to be qualitatively different and not necessarily sequential.

Additional exploratory analyses examined change in cigarettes smoked per day (and therefore the success of individual change) as a predictor of dropout. For those who were followed up at least once post baseline, two categorical variables of at least a $50 \%$ reduction and any positive reduction from baseline to week 4 and week 8 were coded and analysed through univariable binary logistic regression in relation to drop out before week 16 .

All statistical analyses were completed using Stata SE (v. 12.0) (StataCorp LP, College Station, TX, USA).

\section{Results}

The overall sample characteristics for the 99 participants recruited and randomised have been reported elsewhere [49]. Data were collected from $61.6 \%(n=61)$ at 16 weeks post baseline. Study attrition occurred primarily soon after baseline with 21 of the 38 participants lost to follow-up not completing the week 4 assessment.

Table 1 shows that for the sample as a whole those with high self-reported confidence to quit in the next 6 months $(n=48)$ were less likely to be lost to follow-up than those with low confidence. Also, those completing at least 150 mins of moderate and vigorous physical activity (MVPA) per week $(n=69)$ were also less likely to be lost to follow-up.

The multivariable binary logistic regression of variables found to be related to attrition in the univariable analyses Revealed that in the presence of other variables, only the completion of 150 mins of moderate and vigorous physical activity (MVPA) per week or more was related to a lower odds ratio of being lost to follow-up (OR $(95 \% \mathrm{CI}) 0.32(0.13 ; 0.80))$. Confidence to quit in the next 6 months was not related to lower odds of being lost to follow-up (OR $(95 \% \mathrm{CI}) 0.43(0.18 ; 1.03))$.

Table 2 presents descriptive data of the continuous variables between early dropouts, late dropouts and completers. Age, confidence to quit, and smoking history appeared to vary by withdrawal status; younger people, those with lower confidence to quit in the next 6 months, and those with shorter smoking history seemed more likely to drop out early. There also appeared to be a trend for those dropping out early in the study to have left education later and to have reported lower baseline expired air $\mathrm{CO}$ value than those dropping out later. 
Table 1 Summary of logistic regression analysis for study dropout versus completion

\begin{tabular}{|c|c|c|c|}
\hline & Variable & Number & Odds ratio $(95 \% \mathrm{Cl})$ \\
\hline \multirow[t]{8}{*}{ Methods } & Trial $\mathrm{rrm}^{\mathrm{a}}$ & & \\
\hline & Intervention & 49 & $1.03(0.46 ; 2.32)$ \\
\hline & Recruitment avenue $^{\mathrm{b}}$ & & \\
\hline & Stop Smoking Services & 31 & $0.81(0.33 ; 1.99)$ \\
\hline & Community & 6 & $0.74(0.13 ; 4.35)$ \\
\hline & Recruitment method ${ }^{c}$ & & \\
\hline & Letter plus telephone reminder & 38 & $2.24(0.95 ; 5.26)$ \\
\hline & Community & 6 & $1.12(0.19 ; 6.70)$ \\
\hline \multirow{10}{*}{ Demographics } & Age (years) & 99 & $0.97(0.93 ; 1.01)$ \\
\hline & Gender $^{d}$ & & \\
\hline & Female & 56 & $1.55(0.68 ; 3.56)$ \\
\hline & Body mass index & 98 & $1.01(0.95 ; 1.07)$ \\
\hline & Employment status $^{\mathrm{e}}$ & & \\
\hline & Unemployed & 45 & $1.13(0.50 ; 2.55)$ \\
\hline & Job status ${ }^{\mathrm{f}}$ & & \\
\hline & C2-D & 45 & $1.21(0.27 ; 5.50)$ \\
\hline & Unemployed & 45 & $1.33(0.29 ; 6.03)$ \\
\hline & Age left education & 99 & $0.93(0.73 ; 1.17)$ \\
\hline \multirow[t]{12}{*}{ Smoking-related variables } & Years smoking & 99 & $0.98(0.94 ; 1.01)$ \\
\hline & Previous use of Stop Smoking Services ${ }^{g}$ & & \\
\hline & Have not used Stop Smoking Services in the past & 58 & $1.14(0.50 ; 2.60)$ \\
\hline & Cigarettes per day & 99 & $1.00(0.97 ; 1.03)$ \\
\hline & Expired air carbon monoxide (parts per million) & 98 & $1.04(0.99 ; 1.09)$ \\
\hline & Fagerström Test for Nicotine Dependence & 99 & $1.19(0.96 ; 1.46)$ \\
\hline & Importance of quitting next 6 months (median) ${ }^{\mathrm{h}}$ & & \\
\hline & High importance & 49 & $1.23(0.54 ; 2.76)$ \\
\hline & Confidence to quit in the next 6 months (median) ${ }^{i}$ & & \\
\hline & High confidence & 48 & $0.43(0.19 ; 0.99)$ \\
\hline & Confidence to cut down by half in the next month (median) $)^{j}$ & & \\
\hline & High confidence & 39 & $1.44(0.63 ; 3.28)$ \\
\hline \multirow[t]{12}{*}{ Physical activity-related variables } & Self-reported $\geq 30$ mins of moderate and vigorous physical activity per day ${ }^{k}$ & & \\
\hline & Yes & 65 & $0.48(0.20 ; 1.12)$ \\
\hline & Self-reported minutes of moderate and vigorous physical activity per day & 99 & $1.00(0.99 ; 1.00)$ \\
\hline & Self-reported $\geq 30$ mins moderate and vigorous physical activity on at least 5 & days' & \\
\hline & Yes & 43 & $0.77(0.34 ; 1.75)$ \\
\hline & Self-reported $\geq 150$ mins moderate and vigorous physical activity per week ${ }^{m}$ & & \\
\hline & Yes & 69 & $0.33(0.14 ; 0.81)$ \\
\hline & Accelerometer $\geq 30$ mins moderate and vigorous physical activity per day ${ }^{n}$ & & \\
\hline & Yes & 32 & $1.11(0.42 ; 2.95)$ \\
\hline & Accelerometer minutes moderate and vigorous physical activity per day & 66 & $1.00(0.98 ; 1.02)$ \\
\hline & Stage of change to use physical activity to control smoking ${ }^{\circ}$ & & \\
\hline & Planning, action, maintenance & 20 & $0.42(0.15 ; 1.40)$ \\
\hline
\end{tabular}


Table 1 Summary of logistic regression analysis for study dropout versus completion (Continued)

\begin{tabular}{|c|c|c|}
\hline \multicolumn{3}{|c|}{ Confidence to exercise for $\geq 30$ mins on most days over next 6 months ${ }^{p}$} \\
\hline High confidence & 55 & $0.83(0.37 ; 1.86)$ \\
\hline \multicolumn{3}{|c|}{ Confidence to walk for $\geq 15$ mins at a brisk pace ${ }^{q}$} \\
\hline High confidence & 59 & $1.06(0.47 ; 2.43)$ \\
\hline \multicolumn{3}{|c|}{ Indicated mental health problem ${ }^{r}$} \\
\hline Yes & 41 & $1.49(0.65 ; 3.38)$ \\
\hline
\end{tabular}

${ }^{\mathrm{a}}$ Reference: control; ${ }^{\mathrm{b}}$ Reference: primary care; ${ }^{\mathrm{C}}$ Reference: letter only; ${ }^{\mathrm{d}}$ Reference: male; ${ }^{\mathrm{e}}$ Reference: employed; ${ }^{\mathrm{f}}$ Reference: social class A-C1; ${ }^{9}$ Reference: have used SSS in the past; ${ }^{h}$ Reference: low importance; 'Reference: low confidence; ${ }^{\text {R}}$ Reference: low confidence; ${ }^{\mathrm{k}}$ Reference: not reporting 30 mins MVPA per day; 'Reference: not completing 30 mins MVPA on at least 5 days per week; ${ }^{\mathrm{m}}$ Reference: not reporting $>150$ mins MVPA per week; ${ }^{\mathrm{n}}$ Reference: not completing 30 mins MVPA per day as assessed by accelerometer; ${ }^{\circ}$ Reference: pre-contemplation and contemplation; ${ }^{\mathrm{p}}$ Reference: low confidence; ${ }^{\mathrm{a}}$ Reference: low confidence; ${ }^{\mathrm{r}}$ Reference group: no indicated mental health problem

The odds of participant dropout late in the study (versus completion) were increased for those recruited via follow-up telephone calls (Table 3). Greater confidence to quit in the next 6 months was associated with lower odds of late dropout versus completion compared with lower confidence. With increasing age, the odds of early dropout versus completion were reduced, but age did not appear to be associated with odds of late dropout versus completion; years of smoking showed a similar association with both early and late dropout versus completion. Those who reported doing 150 mins or more of MVPA per week at baseline had lower odds of early dropout compared with participants who did not complete at least 150 mins of MVPA per week; however, no equivalent association was found with regard to late dropout.

Variables shown to be related to attrition in the univariable multinomial analyses were carried forward into a multivariable multinomial analysis and are show in Table 4. Only the completion of 150 mins of MVPA per week or more retained any significance in the presence of the other variables, with those completing more than 150 mins of MVPA per week at baseline being less likely to drop out early than later in the study when compared to study completers.

Exploratory analyses of change in cigarettes smoked per day (from baseline to either week 4 or week 8), shown in Table 5, showed no significance in predicting study dropout before week 16 .

Qualitative reasons for dropout were not possible to obtain directly from participants whom we were unable to contact. Of those who explicitly withdrew consent $(n=15)$, the reasons for dropout included illness or death of a close family member, advice from a mental health care worker that the participant had become anxious about involvement in the study, time pressures

Table 2 Comparison of continuous baseline variables by early dropouts, late dropouts, and study completers

\begin{tabular}{|c|c|c|c|c|}
\hline & Number & $\begin{array}{l}\text { Early dropout (before week } \\
\text { 4) }\end{array}$ & $\begin{array}{l}\text { Late dropout (after week } \\
\text { 4) }\end{array}$ & Completer \\
\hline Age; mean (SD), $n$ & 99 & $40.9(10.2), 21$ & $48.2(10.7), 17$ & $48.1(11.4), 61$ \\
\hline Age left education; mean (SD); median (IQR), $n$ & 99 & $16.5(1.3) ; 16(16 ; 17), 21$ & $15.7(0.9) ; 15(15 ; 16), 17$ & $16.4(2.2) ; 16(15 ; 16)$ \\
\hline BMl; mean (SD); median (IQR), $n$ & 98 & $\begin{array}{l}29.0(7.9) ; 28.0(23.2 ; 33.3), \\
21\end{array}$ & $\begin{array}{l}27.5(5.7) ; 27.3(22.1 ; 32.6) \\
17\end{array}$ & $\begin{array}{l}28.0(6.0) ; 27.0(22.5 ; 31.7) \\
60\end{array}$ \\
\hline Years smoking; mean (SD); median (IQR), $n$ & 99 & $\begin{array}{l}25.3(11.9) ; 27.7(12.6 ; 31.8), \\
21\end{array}$ & $\begin{array}{l}35.2(11.6) ; 37.4(24.6 ; 44.7) \\
17\end{array}$ & $\begin{array}{l}33.3(11.9) ; 35.8(23.4 ; 43.1), \\
61\end{array}$ \\
\hline CPD; mean (SD); median (IQR), $n$ & 99 & $\begin{array}{l}19.2(7.6) ; 19.8(13.3 ; 27.8), \\
21\end{array}$ & $\begin{array}{l}23.7(21.2) ; 19.6(15.0 ; 27.8) \\
17\end{array}$ & $\begin{array}{l}21.8(13.8) ; 18.9(15.0 ; 23.9), \\
61\end{array}$ \\
\hline $\mathrm{CO}$; mean (SD); median (IQR), $n$ & 98 & $17.9(10.0) ; 14(11 ; 21), 21$ & $21.6(5.2) ; 21.5(17.5 ; 24), 16$ & $17.1(7.8) ; 16(12 ; 22), 61$ \\
\hline FTND; mean (SD), $n$ & 99 & $5.7(1.8), 21$ & $6.4(2.2), 17$ & $5.3(2.1), 61$ \\
\hline $\begin{array}{l}\text { Self-reported MVPA per day; mean (SD); median } \\
(\text { (IQR), } n\end{array}$ & 99 & $\begin{array}{l}72.3(91.0) ; 42.1(0 ; 109.3) \\
21\end{array}$ & $\begin{array}{l}43.33(49.3) ; 34.3(0 ; 111.4) \\
17\end{array}$ & $\begin{array}{l}81.0(98.6) ; 47.1(77.1 ; 25.7), \\
61\end{array}$ \\
\hline Accelerometer MVPA; mean (SD); median (IQR), $n$ & 66 & $\begin{array}{l}29.3(20.4) ; 27.6(13.2 ; 42.5) \\
19\end{array}$ & $\begin{array}{l}41.3(32.8) ; 35.3(16.3 ; 44.9) \\
9\end{array}$ & $\begin{array}{l}31.0(24.3) ; 25.8(11.8 ; 43.7) \\
38\end{array}$ \\
\hline $\begin{array}{l}\text { Importance of quitting in next } 6 \text { months; mean (SD); } \\
\text { median (IQR), } n\end{array}$ & 99 & $5.4(1.5) ; 6(4 ; 7), 21$ & $5.1(2.0) ; 6(4 ; 7), 17$ & $5.3(1.7) ; 5(5 ; 7), 61$ \\
\hline Confidence to quit in next 6 months; mean (SD), $n$ & 97 & $3.1(1.4), 21$ & $2.7(1.5), 17$ & $3.9(1.7), 59$ \\
\hline
\end{tabular}

$S D$ standard deviation, IQR interquartile range, $B M I$ body mass index, CPD cigrettes per day , CO carbon monoxide, FTND Fagerström Test for Nicotine Dependence, MVPA moderate and vigorous physical activity 
Table 3 Summary of multinomial logistic regression analysis for study completion status: late/early dropout versus completion

\begin{tabular}{|c|c|c|c|c|c|}
\hline & \multirow[b]{2}{*}{ Variable } & \multicolumn{2}{|c|}{ Early dropouts (before week 4) } & \multicolumn{2}{|c|}{ Late dropouts (after week 4} \\
\hline & & Number & $\begin{array}{l}\text { Odds ratio } \\
(95 \% \mathrm{Cl})\end{array}$ & Number & $\begin{array}{l}\text { Odds ratio } \\
(95 \% \mathrm{Cl})\end{array}$ \\
\hline & Trial $\mathrm{arm}^{\mathrm{a}}$ & & & & \\
\hline & Intervention & 9 & $0.78(0.29 ; 2.10)$ & 10 & $1.43(0.50 ; 4.39)$ \\
\hline \multirow[t]{6}{*}{ Recruitment } & Recruitment avenue ${ }^{b}$ & & & & \\
\hline & Stop Smoking Services & 6 & $0.79(0.26 ; 2.39)$ & 5 & $0.84(0.26 ; 2.77)$ \\
\hline & Community & 1 & $0.66(0.07 ; 6.42)$ & 1 & $0.84(0.08 ; 8.33)$ \\
\hline & Recruitment method ${ }^{c}$ & & & & \\
\hline & Telephone & 9 & $1.63(0.58 ; 4.62)$ & 10 & $3.32(1.05 ; 10.60)$ \\
\hline & Community & 1 & $0.86(0.87 ; 8.58)$ & 1 & $1.58(0.15 ; 16.61)$ \\
\hline \multirow[t]{10}{*}{ Demographics } & Age (years) & 21 & $0.94(0.90 ; 0.99)$ & 17 & $1.00(0.95 ; 1.05)$ \\
\hline & Gender $^{d}$ & & & & \\
\hline & Female & 13 & $1.48(0.53 ; 5.05)$ & 11 & $1.67(0.54 ; 5.05)$ \\
\hline & Body mass index & 21 & $1.02(0.95 ; 1.11)$ & 17 & $0.99(0.33 ; 1.08)$ \\
\hline & Employment status ${ }^{\mathrm{e}}$ & & & & \\
\hline & Unemployed & 7 & $0.63(0.22 ; 1.79)$ & 11 & $2.32(0.76 ; 7.03)$ \\
\hline & Job status ${ }^{f}$ & & & & \\
\hline & $C 2-E$ & 13 & $2.77(0.30 ; 25.53)$ & 4 & $0.43(0.06 ; 2.92)$ \\
\hline & Unemployed & 7 & $1.55(0.16 ; 15.18)$ & 11 & $1.22(0.21 ; 7.03)$ \\
\hline & Age left education & 21 & $1.04(0.82 ; 1.31)$ & 17 & $0.64(0.36 ; 1.14)$ \\
\hline \multirow[t]{3}{*}{ Smoking history } & Years smoking & & $0.95(0.90 ; 0.99)$ & & $1.16(0.97 ; 1.06)$ \\
\hline & Previous use of Stop Smoking Services ${ }^{9}$ & & & & \\
\hline & No & 14 & $01.49(0.53 ; 4.22)$ & 9 & $0.84(0.28 ; 2.46)$ \\
\hline \multirow{9}{*}{$\begin{array}{l}\text { Smoking-related } \\
\text { variables }\end{array}$} & Cigarettes per day & 21 & $0.82(0.94 ; 1.03)$ & 17 & $1.01(0.97 ; 1.04)$ \\
\hline & Expired air carbon monoxide (parts per million) & 21 & $1.01(0.95 ; 1.08)$ & 16 & $1.07(1.00 ; 1.14)$ \\
\hline & Fagerstrom Test for Nicotine Dependence & 21 & $1.01(0.86 ; 1.42)$ & 17 & $1.31(0.98 ; 1.73)$ \\
\hline & Importance of quitting in the next 6 months (median) & & & & \\
\hline & High 6-7 & 11 & $1.21(0.45 ; 3.29)$ & 9 & $1.24(0.42 ; 3.63)$ \\
\hline & Confidence to quit in the next 6 months (median) & & & & \\
\hline & High 4-7 & 12 & $0.55(0.20 ; 1.51)$ & 10 & $0.31(0.95 ; 0.98)$ \\
\hline & Confidence to cut down by half in the next month (median) & & & & \\
\hline & High 5-7 & 3 & $1.95(0.71 ; 5.31)$ & 2 & $0.97(0.31 ; 2.97)$ \\
\hline \multirow{10}{*}{$\begin{array}{l}\text { Physical activity- } \\
\text { related variables }\end{array}$} & \multicolumn{5}{|l|}{ Self-reported $\geq 30$ mins of moderate and vigorous physical activity per dayk } \\
\hline & Yes & 11 & $0.42(0.15 ; 1.19)$ & 10 & $0.55(0.18 ; 1.68)$ \\
\hline & Self-reported minutes of moderate and vigorous physical activity per day & 21 & $1.00(0.99 ; 1.00)$ & 17 & $0.99(0.98 ; 1.00)$ \\
\hline & \multicolumn{5}{|c|}{ Self-reported $\geq 30$ mins of moderate and vigorous physical activity on at least 5 days ${ }^{\prime}$} \\
\hline & Yes & 9 & $0.89(0.33 ; 2.41)$ & 6 & $0.64(0.21 ; 1.95)$ \\
\hline & \multicolumn{5}{|l|}{ Self-reported $\geq 150$ mins of moderate and vigorous physical activity per week ${ }^{m}$} \\
\hline & Yes & 11 & $0.30(0.10 ; 0.85)$ & 10 & $0.39(0.12 ; 1.21)$ \\
\hline & \multicolumn{5}{|l|}{ Accelerometer $\geq 30$ mins of moderate and vigorous physical activity per day ${ }^{n}$} \\
\hline & Yes & 8 & $0.81(0.27 ; 2.46)$ & 6 & $2.23(0.48 ; 10.18)$ \\
\hline & Accelerometer total minutes of moderate and vigorous physical & 19 & $1.00(0.97 ; 1.02)$ & 9 & $0.54(0.99 ; 1.04)$ \\
\hline
\end{tabular}


Table 3 Summary of multinomial logistic regression analysis for study completion status: late/early dropout versus completion (Continued)

\begin{tabular}{|c|c|c|c|c|}
\hline \multicolumn{5}{|c|}{ Stage of change to use physical activity to control smoking ${ }^{\circ}$} \\
\hline Planning, action, maintenance & 2 & $0.32(0.07 ; 1.55)$ & 3 & $0.66(0.17 ; 2.61)$ \\
\hline \multicolumn{5}{|c|}{ Confidence to exercise for $\geq 30$ mins on most days over next 6 months $^{p}$} \\
\hline High (6-7) & 12 & $0.99(0.36 ; 2.69)$ & 8 & $0.66(0.23 ; 1.93)$ \\
\hline \multicolumn{5}{|c|}{ Confidence to walk for $\geq 15$ mins at a brisk pace ${ }^{q}$} \\
\hline High (7) & 12 & $0.46(0.34 ; 2.53)$ & 11 & $1.27(0.41 ; 3.90)$ \\
\hline \multicolumn{5}{|l|}{ Indicated mental health problem ${ }^{r}$} \\
\hline Yes & 11 & $1.82(0.67 ; 4.95)$ & 7 & $1.16(0.39 ; 3.46)$ \\
\hline
\end{tabular}

${ }^{\mathrm{a}}$ Reference: control; ${ }^{\mathrm{b}}$ Reference: primary care; ${ }^{\mathrm{C}}$ Reference: letter only; ${ }^{\mathrm{d}}$ Reference: male; ${ }^{\mathrm{e}}$ Reference: employed; ${ }^{\mathrm{f}}$ Reference: social class A-C1; ${ }^{9}$ Reference: have used SSS in the past; ${ }^{\mathrm{h}}$ Reference: low importance; ${ }^{\mathrm{i}}$ Reference: low confidence; ${ }^{j}$ Reference: low confidence; ${ }^{\mathrm{k}}$ Reference: not reporting 30 mins MVPA per day; 'Reference: not completing 30 mins MVPA on at least 5 days per week; ${ }^{\mathrm{m}}$ Reference: not reporting $>150$ mins MVPA per week; ${ }^{\mathrm{n}}$ Reference: not completing 30 mins MVPA per day as assessed by accelerometer; ${ }^{\circ}$ Reference: pre-contemplation and contemplation; ${ }^{p}$ Reference: low confidence; ${ }^{9}$ Reference: low confidence; ${ }^{\mathrm{r}}$ Reference group: no indicated mental health problem

elsewhere, expecting a greater financial reward for taking part (indicating a possible misunderstanding of study procedures due to poor explanation), and being dissatisfied with allocation to the control condition.

\section{Discussion}

The overall attrition rate of $38.4 \%$ at 16 weeks falls within the range of attrition rates identified in other broader trials of smoking cessation. In the absence of similar studies, the overall retention in this study could be regarded as acceptable for a group of disadvantaged smokers and provides valuable information for a larger study. Unlike some trials, we did not explicitly pay participants to complete follow-up assessments and one may assume a lower attrition rate had we done so.

The fact that over $50 \%$ of those dropping out did so before week 4 suggests that particular focus is needed on new ways to maintain participation in the initial stages of trial engagement. Although attrition in both treatment arms was the same in the present study, it may be that the predictors of attrition may vary between arms. However, the numbers in this pilot trial were insufficient to inferentially test this hypothesis.

The only trial design factors to influence attrition was whether or not participants were recruited by follow-up telephone call; those recruited by this more intensive approach were more likely to drop out later than earlier in the study, possibly reflecting ambivalence to the invitation. We deliberately conducted follow-up telephone calls to recruit smokers in case they had low literacy levels. It may be that providing further data after baseline was too challenging and we should consider providing more support to keep these individuals in the study. Recruitment via different locations (primary care versus SSS), and the method of recruitment, also showed no effect on attrition in the sample as a whole. We found equal attrition in both the intervention and control arms, which has been reported elsewhere [43].

The mean age of those dropping out early in the study was younger than the mean age of those completing the study. Age has been reported elsewhere to predict attrition, with older participants less likely to drop out [57], suggesting they may be more committed and able to

Table 4 Multivariable multinomial logistic regression for study completion status: late/early dropout versus completion ( $N=97)$

\begin{tabular}{|c|c|c|c|c|}
\hline \multirow[b]{2}{*}{ Variable } & \multicolumn{2}{|c|}{ Early dropouts (before week 4) } & \multicolumn{2}{|c|}{ Late dropouts (after week 4) } \\
\hline & Number & Odds ratio $(95 \% \mathrm{Cl})$ & Number & Odds ratio $(95 \% \mathrm{Cl})$ \\
\hline \multicolumn{5}{|c|}{ Self-reported $\geq 150$ minutes of moderate and vigorous physical activity per week ${ }^{m}$} \\
\hline Yes & 11 & $0.23(0.07 ; 0.75)$ & 10 & $0.52(0.14 ; 1.90)$ \\
\hline \multicolumn{5}{|c|}{ Confidence to quit in the next 6 months (median) ${ }^{i}$} \\
\hline High (4-7) & 9 & $0.50(0.16 ; 1.51)$ & 5 & $0.37(0.11 ; 1.27)$ \\
\hline \multicolumn{5}{|c|}{ Recruitment method ${ }^{c}$} \\
\hline Telephone & 9 & $1.25(0.39 ; 4.01)$ & 10 & $2.77(0.79 ; 9.78)$ \\
\hline Community & 1 & $0.51(0.42 ; 6.17)$ & 1 & $1.72(0.14 ; 21.33)$ \\
\hline Age (years) & 21 & $1.00(0.85 ; 1.17)$ & 17 & $0.84(0.65 ; 1.06)$ \\
\hline Years smoking & 21 & $0.94(0.81 ; 1.09)$ & 17 & $1.21(0.95 ; 1.54)$ \\
\hline
\end{tabular}

${ }^{\mathrm{a}}$ Reference: not reporting $>150$ minutes MVPA per week; ${ }^{\mathrm{b}}$ Reference: low confidence; ${ }^{\mathrm{c}}$ Reference: letter only 
Table $\mathbf{5}$ Logistic regression of study attrition for change in cigarettes smoked per day before week $16(N=78)$ (late dropout versus completion)

\begin{tabular}{lcc}
\hline Variable & Number & Odds ratio $(95 \% \mathrm{Cl})$ \\
\hline Reduction of $50 \%$ or more before week 16 & \\
Yes & 28 & $0.31(0.08 ; 1.19)$ \\
Any reduction in cigarettes smoked per day before week 16 \\
Yes & 58 & $0.55(0.17 ; 1.74)$ \\
\hline
\end{tabular}

have more time to remain in a trial [1]. This highlights the need for additional support for engaging younger people. However, other studies have not found age to be related to attrition $[9,50]$. No other participant demographic characteristics showed evidence of any relationship with study attrition. Our researchers worked flexible hours to conduct assessments with participants (in employment or not), and this may have reduced the risk of attrition.

We were interested in whether we could retain more dependent and heavier smokers in the trial. The finding that those with a longer smoking history and a trend for smoking more cigarettes were more likely to complete the study was encouraging. They may suggest that a trial focused on cutting down may be more appealing to heavier smokers, a finding reported elsewhere [58]. In contrast it appeared that those with greater confidence to quit (normally associated with lower dependence) were less likely to withdraw, specifically, less likely to withdraw later in the study. These preliminary contrasting findings are not easy to explain but it would appear that future researchers should stress that smoking behaviour and related beliefs (such as confidence to quit) should not influence continued participation in a trial.

In smoking cessation studies, smoking relapse is typically associated with attrition and, similarly, it may be that a failure to reduce smoking levels is associated with attrition. Also, several of the variables shown to predict attrition in the present study are the same as those that predict smoking relapse (e.g. low self-efficacy, lower age) and there may be a common set of variables that predict smoking relapse, failure to reduce and attrition. There may also be variables that are specific to smoking reduction versus cessation studies. For example, a higher level of cigarette dependence reliably predicts smoking relapse [59] but in the current study higher dependence was associated with less attrition.

Those who completed at least 150 mins of MVPA per week at baseline were also less likely to withdraw than those reporting less activity; specifically, these participants were less likely to withdraw early in the study. This finding remained significant even in the presence of other predictor variables in the multivariable model.
This replicates the findings from another study in which those who were inactive at baseline were significantly more likely to drop out of an arm of a trial with a focus on fitness training [60]. Greater study attrition among less active participants in a physical activity study has the potential to reduce the size of effects due to a ceiling effect. It also poses a threat to external validity if the findings cannot be generalised to less active populations. Other research involving low socioeconomic groups on the effectiveness of a physical activity intervention [60] reported that attrition rates were significantly higher in those randomised to a 'fitness assessment' intervention compared with an 'exercise consultation' intervention. This suggests that intervention content may differentially influence attrition. The present study involved physical activity (PA) counselling (as opposed to an emphasis on 'fitness') and this may have helped to increase study retention. Avoiding an emphasis on 'fitness' may have helped to maximise external validity by engaging with and retaining both those who are and are not already physically active. However, the current study engaged with a comparatively active sample (potentially due to self-selection), meaning analyses may be less likely to show an effect (due to a ceiling effect). It also limits the application of the findings to a more general, less active, population. The levels of self-reported physical activity were not corroborated by objective activity measurement at baseline (accelerometer) and due to the low numbers and variance in self-reported physical activity, more research is needed to further explore if baseline physical activity influences study attrition.

Failure or success to reduce the amount of cigarettes smoked between baseline and week 8 showed no confidence in predicting dropout before week 16. This is likely limited by the lack of precision due to the small sample size, as the trend was in favour of those who achieved a reduction in cigarettes smoked before week 16 to demonstrate lower odds of withdrawal, as might be expected.

The present exploratory study had several limitations. Due to the relatively low numbers involved in this pilot trial (and as a result the low number of observations of the outcome of interest), some caution should be used in interpreting the findings due to their imprecision. Nevertheless, we have identified how the findings may influence planning a larger study, and further such analysis should be considered in any future larger study to estimate bias from missing data and study attrition.

The study was also limited in the ethnic diversity of the sample, with $97 \%$ reporting being white British, which is typical of the geographical area in which the study was located. This limits the findings to other more ethnically diverse populations and is something that would need to be considered carefully in future research 
(as ethnicity is something that has been found to be predictive of dropout in other studies [1]).

We chose not to incentivise data capture to avoid the potential of influencing trial outcomes in this pragmatic study. Preliminary work also revealed that financial incentive was treated with caution by some participants for fear of jeopardising government unemployment benefits. The payment for returning an accelerometer was implemented in an attempt to minimise the loss of expensive equipment and not as an incentive for participation, although it may have acted as such. Incentivisation could be considered for future research in more detail.

\section{Conclusions}

The present research provides important information on factors that may influence attrition within a multicomponent smoking reduction study among low socioeconomic status smokers. Retention was at least comparable with the few other studies involving disadvantaged groups with smoking behaviour as a main outcome. These analyses provide unique information on retention in a study aimed at smokers in these groups who did not wish to quit. Only a few factors were quantitatively associated with attrition, suggesting that further research is needed to explain why participants in this type of study drop out. Qualitatively, the diverse reasons for study attrition appeared to be mainly due to unpredictable participant life events and perhaps a misunderstanding about trial involvement.

\section{Abbreviations}

CO: Carbon monoxide; CTIMP: Clinical trial of an investigational medicinal product; EARS: Exercise-Assisted Reduction then Stop; FTND: Fagerström Test for Nicotine Dependence; HTA: Health Technology Assessment;

ISRCTN: International Standardised Randomised Controlled Trial Number; ITT: Intention to treat; MVPA: Moderate and vigorous physical activity; NHS: National Health Service; NRT: Nicotine replacement therapy; PA: Physical activity; RCT: Randomised controlled trial; SSS: Stop smoking services; UKCRN: United Kingdom Clinical Research Network

\section{Acknowledgements}

The team would like to acknowledge and thank: the three researchers working as Health Trainers on the project (Julie Lloyd, Maggie Kelly, and Mel Fairbairn) for their insights and tireless efforts in retaining participants in the trial; Naomi Southern for her diligent administrative support throughout; Russ Moody and his team at the Stop Smoking Services in Plymouth for their support; all the staff at the various GP practices involved; and to all the broader community contacts who supported recruitment.

\section{Funding}

This article presents independent research funded by the National Institute for Health Research (NIHR) under its Health Technology Assessment Research Programme (Grant Reference Number 07/78/02). The views expressed are those of the authors and not necessarily those of the NHS, the NIHR or the Department of Health.

Richard Byng's contribution to this research was funded by the National Institute for Health Research (NIHR) Collaboration for Leadership in Applied Health Research and Care South West Peninsula at the Royal Devon and Exeter NHS Foundation Trust. The views expressed are those of the authors and not necessarily those of the NHS, the NIHR or the Department of Health.

\section{Availability of data and materials}

The datasets during and/or analysed during the current study are available from the corresponding author on reasonable request.

\section{Authors' contributions}

AHT (as Principal Investigator) had overall responsibility for the study and $\Pi T$ was responsible for the day-to-day operationalisation and management of the study. Initial drafting of the text was done by $\Pi \mathrm{T}$ and AHT. TT, FW, and AHT were involved in completing the statistical analyses. TT, AHT, FW, RT, PA, $R W, S M, M U, R B, J C, C G$, and RA were involved in all stages of the work: the design, development of methods, analysis and commenting upon and drafting the final manuscript. All authors approved the final manuscript.

\section{Competing interests}

PA has been a consultant and done research for manufacturers of smoking cessation products.

RW has undertaken research and consultancy for companies that develop and manufacture smoking cessation medications. He is co-Director of the National Centre for Smoking Cessation and Training and a trustee of the stop-smoking charity, QUIT. He has a share of a patent on a novel nicotine delivery device. All other authors have declared no competing interests.

\section{Consent for publication}

Not applicable.

\section{Ethics approval and consent to participate}

Ethical approval for the study was granted by the NHS National Research Ethics Service Committee South West, in the UK (10/H0106/59). Participants provided informed consent before entering the trial.

\section{Author details}

${ }^{1}$ Plymouth University Peninsula School of Medicine and Dentistry, Plymouth, UK. ${ }^{2}$ University of Exeter Medical School, Exeter, UK. ${ }^{3}$ Nuffield Department of Primary Care Health Sciences, University of Oxford, Oxford, UK. ${ }^{4}$ Institute of Population Health Research, St George's University of London, Cranmer Terrace, London, UK. ${ }^{5}$ Research Department of Clinical, Educational and Health Psychology, University College London, 1-19 Torrington Place, London, UK. ${ }^{6}$ Health Behaviour Research Centre, Department of Epidemiology and Public Health, University College London, Gower Street, London, UK.

Received: 9 September 2015 Accepted: 6 October 2016

Published online: 27 October 2016

\section{References}

1. Leeman RF, Quiles ZN, Molinelli LA, Terwal DM, Nordstrom BL, Garvey AJ, Kinnunen T. Attrition in a multi-component smoking cessation study for females. Tob Induc Dis. 2006;3(2):59-71.

2. Peterson JC, Pirraglia PA, Wells MT, Charlson ME. Attrition in longitudinal randomized controlled trials: home visits make a difference. BMC Med Res Methodol. 2012;12:178.

3. Heijmans $\mathrm{N}$, van Lieshout J, Wensing M. Improving participation rates by providing choice of participation mode: two randomized controlled trials. BMC Med Res Methodol. 2015;15:29.

4. West R, Hajek P, Stead L, Stapleton J. Outcome criteria in smoking cessation trials: proposal for a common standard. Addiction. 2005;100(3):299-303.

5. Kaper J, Wagena EJ, Willemsen MC, van Schayck CP. Reimbursement for smoking cessation treatment may double the abstinence rate: results of a randomized trial. Addiction. 2005;100(7):1012-20.

6. Twardella D, Brenner $\mathrm{H}$. Effects of practitioner education, practitioner payment and reimbursement of patients' drug costs on smoking cessation in primary care: a cluster randomised trial. Tob Control. 2007;16(1):15-21.

7. Borland R, Balmford J, Hunt D. The effectiveness of personally tailored computer-generated advice letters for smoking cessation. Addiction. 2004; 99(3):369-77.

8. Stockton MC, McMahon SD, Jason LA. Gender and smoking behavior in a worksite smoking cessation program. Addict Behav. 2000;25(3):347-60.

9. Nevid JS, Javier RA. Preliminary investigation of a culturally specific smoking cessation intervention for Hispanic smokers. Am J Health Promot. 1997;11(3):198-207. 
10. Hedeker D, Mermelstein RJ, Demirtas H. Analysis of binary outcomes with missing data: missing = smoking, last observation carried forward, and a little multiple imputation. Addiction. 2007;102(10):1564-73.

11. Barnes SA, Larsen MD, Schroeder D, Hanson A, Decker PA. Missing data assumptions and methods in a smoking cessation study. Addiction. 2010;105(3):431-7.

12. Twardella $\mathrm{D}$, Brenner $\mathrm{H}$. Implications of nonresponse patterns in the analysis of smoking cessation trials. Nicotine Tob Res. 2008;10(5):891-6.

13. Lancaster T, Stead LF. Individual behavioural counselling for smoking cessation. Cochrane Database Syst Rev. 2005;2, CD001292.

14. Kim JR, Lee MS, Hwang JY, Lee JD. Efficacy of a smoking cessation intervention using the AHCPR guideline tailored for Koreans: a randomized controlled trial. Health Promot Int. 2005;20(1):51-9.

15. Rigotti NA, Arnsten JH, McKool KM, Wood-Reid KM, Pasternak RC, Singer DE. Efficacy of a smoking cessation program for hospital patients. Arch Intern Med. 1997;157(22):2653-60

16. Simon JA, Carmody TP, Hudes ES, Snyder E, Murray J. Intensive smoking cessation counseling versus minimal counseling among hospitalized smokers treated with transdermal nicotine replacement: a randomized trial. Am J Med. 2003;114(7):555-62.

17. Aveyard P, Brown K, Saunders C, Alexander A, Johnstone E, Munafo MR, Murphy M. Weekly versus basic smoking cessation support in primary care: a randomised controlled trial. Thorax. 2007;62(10):898-903.

18. Stead LF, Lancaster T. Combined pharmacotherapy and behavioural interventions for smoking cessation. Cochrane Database Syst Rev. 2012;10, CD008286

19. Katz DA, Muehlenbruch DR, Brown RL, Fiore MC, Baker TB. Effectiveness of implementing the agency for healthcare research and quality smoking cessation clinical practice guideline: a randomized, controlled trial. J Natl Cancer Inst. 2004;96(8):594-603.

20. Chan SS, Leung DY, Abdullah AS, Lo SS, Yip AW, Kok WM, Ho SY, Lam TH. Smoking-cessation and adherence intervention among Chinese patients with erectile dysfunction. Am J Prev Med. 2010;39(3):251-8.

21. Segnan N, Ponti A, Battista RN, Senore C, Rosso S, Shapiro SH, Aimar D. A randomized trial of smoking cessation interventions in general practice in Italy. Cancer Causes \& Control: CCC. 1991;2(4):239-46.

22. Binnie VI, McHugh S, Jenkins W, Borland W, Macpherson LM. A randomised controlled trial of a smoking cessation intervention delivered by dental hygienists: a feasibility study. BMC Oral Health. 2007;7:5.

23. Mohiuddin SM, Mooss AN, Hunter CB, Grollmes TL, Cloutier DA, Hilleman DE. Intensive smoking cessation intervention reduces mortality in high-risk smokers with cardiovascular disease. Chest. 2007;131(2):446-52.

24. Lancaster T, Stead LF. Self-help interventions for smoking cessation. Cochrane Database Syst Rev. 2005;3, CD001118.

25. Dijkstra A, De Vries H, Roijackers J. Targeting smokers with low readiness to change with tailored and nontailored self-help materials. Prev Med. 1999;28(2):203-11.

26. Nollen N, Ahluwalia JS, Mayo MS, Richter K, Choi WS, Okuyemi KS, Resnicow K. A randomized trial of targeted educational materials for smoking cessation in African Americans using transdermal nicotine. Health Educ Behav. 2007;34(6): 911-27.

27. Becona E, Vazquez FL. Effectiveness of personalized written feedback through a mail intervention for smoking cessation: a randomized-controlled trial in Spanish smokers. J Consult Clin Psychol. 2001;69(1):33-40.

28. Strecher VJ, Marcus A, Bishop K, Fleisher L, Stengle W, Levinson A, Fairclough DL, Wolfe P, Morra M, Davis S, et al. A randomized controlled trial of multiple tailored messages for smoking cessation among callers to the cancer information service. J Health Commun. 2005;10 Suppl 1:105-18.

29. Bryant J, Bonevski B, Paul C, McElduff P, Attia J. A systematic review and meta-analysis of the effectiveness of behavioural smoking cessation interventions in selected disadvantaged groups. Addiction. 2011;106(9): 1568-85.

30. Ranney L, Melvin C, Lux L, McClain E, Lohr KN. Systematic review: smoking cessation intervention strategies for adults and adults in special populations. Ann Intern Med. 2006;145(11):845-56.

31. Collins BN, Wileyto EP, Hovell MF, Nair US, Jaffe K, Tolley NM, AudrainMcGovern J. Proactive recruitment predicts participant retention to end of treatment in a secondhand smoke reduction trial with low-income maternal smokers. Transl Behav Med. 2011;1(3):394-9.

32. Lindson-Hawley N, Aveyard P, Hughes JR. Reduction versus abrupt cessation in smokers who want to quit. Cochrane Database Syst Rev. 2012;11, CD008033.
33. Cummings KM, Emont SL, Jaen C, Sciandra R. Format and quitting instructions as factors influencing the impact of a self-administered quit smoking program. Health Educ Q. 1988;15(2):199-216.

34. Hughes JR, Solomon LJ, Livingston AE, Callas PW, Peters EN. A randomized, controlled trial of NRT-aided gradual vs. abrupt cessation in smokers actively trying to quit. Drug Alcohol Depend. 2010;111(1-2):105-13.

35. Etter JF, Huguelet P, Perneger TV, Cornuz J. Nicotine gum treatment before smoking cessation: a randomized trial. Arch Intern Med. 2009; 169(11):1028-34.

36. Curry SJ, Marlatt GA, Gordon J, Baer JS. A comparison of alternative theoretical approaches to smoking cessation and relapse. Health Psychol. 1988;7(6):545-56.

37. Ussher MH, Taylor A, Faulkner G. Exercise interventions for smoking cessation. Cochrane Database Syst Rev. 2012;1, CD002295.

38. Hill JS. Effect of a program of aerobic exercise on the smoking behaviour of a group of adult volunteers. Can J Public Health. 1985;76:183-6.

39. McKay HG, Danaher BG, Seeley JR, Lichtenstein E, Gau JM. Comparing two web-based smoking cessation programs: randomized controlled trial. J Med Internet Res. 2008;10(5), e40.

40. Marcus BH, Albrecht AE, Niaura RS, Abrams DB, Thompson PD. Usefulness of physical exercise for maintaining smoking cessation in women. Am J Cardiol. 1991;68(4):406-7.

41. Marcus BH, Lewis BA, Hogan J, King TK, Albrecht AE, Bock B, Parisi AF, Niaura R, Abrams DB. The efficacy of moderate-intensity exercise as an aid for smoking cessation in women: a randomized controlled trial. Nicotine Tob Res. 2005;7(6):871-80.

42. Bernard P, Ninot G, Cyprien F, Courtet P, Guillaume S, Georgescu V, Quantin $X$. Exercise and counseling for smoking cessation in smokers with depressive symptoms: a randomized controlled pilot trial. J Dual Diagn. 2015;11(3-4):205-16.

43. Vickers KS, Patten CA, Lewis BA, Clark MM, Ussher M, Ebbert JO, Hurt RD. Feasibility of an exercise counseling intervention for depressed women smokers. Nicotine Tob Res. 2009;11(8):985-95.

44. Ussher M, Lewis S, Aveyard P, Manyonda I, West R, Lewis B, Coleman T. The London exercise and pregnant smokers (LEAP) trial: a randomised controlled trial of physical activity for smoking cessation in pregnancy with an economic evaluation. Health Technol Assess. 2015;19(84):1-135.

45. Richards CM, Sharif F, Eischen S, Thomas J, Wang Q, Guo H, Okuyemi K. Retention of homeless smokers in the power to quit study. Nicotine and Tobacco Research. 2015;17(9):1104-11.

46. Michie S, Jochelson K, Markham WA, Bridle C. Low-income groups and behaviour change interventions: a review of intervention content, effectiveness and theoretical frameworks. J Epidemiol Community Health. 2009;63(8):610-22

47. Crutzen R, Viechtbauer W, Kotz D, Spigt M. No differential attrition was found in randomized controlled trials published in general medical journals: a meta-analysis. J Clin Epidemiol. 2013;66(9):948-54.

48. Wennike P, Danielsson T, Landfeldt B, Westin A, Tonnesen P. Smoking reduction promotes smoking cessation: results from a double blind, randomized, placebo-controlled trial of nicotine gum with 2-year follow-up. Addiction. 2003:98(10):1395-402.

49. Dijkstra A, De Vries H, Roijackers J. Long-term effectiveness of computergenerated tailored feedback in smoking cessation. Health Educ Res. 1998; 13(2):207-14.

50. Curtin L, Brown RA, Sales SD. Determinants of attrition from cessation treatment in smokers with a history of major depressive disorder. Psychol Addict Behav. 2000;14(2):134-42.

51. Humerfelt S, Eide GE, Kvale G, Aaro LE, Gulsvik A. Effectiveness of postal smoking cessation advice: a randomized controlled trial in young men with reduced FEV1 and asbestos exposure. Eur Respir J. 1998;11(2):284-90.

52. Bowen DJ, McTiernan A, Powers D, Feng Z. Recruiting women into a smoking cessation program: who might quit? Women Health. 2000;31(4): 41-58.

53. Thompson T, Greaves C, Ayres R, Aveyard P, Warren F, Byng R, Taylor A. Lessons learned from recruiting socioeconomically disadvantaged smokers into a pilot randomized controlled trial to explore the role of Exercise Assisted Reduction then Stop (EARS) smoking. Trials. 2015;16(1):1.

54. Taylor AH, Thompson TP, Greaves CJ, Taylor RS, Green C, Warren FC, Kandiyali R, Aveyard P, Ayres R, Byng R, et al. A pilot randomised trial to assess the methods and procedures for evaluating the clinical effectiveness and cost-effectiveness of Exercise Assisted Reduction then Stop 
(EARS) among disadvantaged smokers. Health Technol Assess. 2014;18(4):1-324

55. Heatherton TF, Kozlowski LT, Frecker RC, Fagerstrom KO. The Fagerstrom Test for Nicotine Dependence: a revision of the Fagerstrom Tolerance Questionnaire. Br J Addict. 1991;86(9):1119-27.

56. Fagerstrom K. Determinants of tobacco use and renaming the FTND to the Fagerstrom Test for Cigarette Dependence. Nicotine Tob Res. 2012;14(1):75-8.

57. Fortmann SP, Killen JD. Who shall quit? Comparison of volunteer and population-based recruitment in two minimal-contact smoking cessation studies. Am J Epidemiol. 1994;140(1):39-51.

58. Shiffman S, Hughes JR, Ferguson SG, Pillitteri JL, Gitchell JG, Burton SL. Smokers' interest in using nicotine replacement to aid smoking reduction. Nicotine Tob Res. 2007;9(11):1177-82.

59. Vangeli E, Stapleton J, Smit ES, Borland R, West R. Predictors of attempts to stop smoking and their success in adult general population samples: a systematic review. Addiction. 2011:106(12):2110-21.

60. Lowther M, Mutrie N, Scott EM. Promoting physical activity in a socially and economically deprived community: a 12 month randomized control trial of fitness assessment and exercise consultation. J Sports Sci. 2002;20(7):577-88.

\section{Submit your next manuscript to BioMed Central} and we will help you at every step:

- We accept pre-submission inquiries

- Our selector tool helps you to find the most relevant journal

- We provide round the clock customer support

- Convenient online submission

- Thorough peer review

- Inclusion in PubMed and all major indexing services

- Maximum visibility for your research

Submit your manuscript at www.biomedcentral.com/submit 